\title{
Training on professional foreign language for students of engineering specialties: implementation of electronic technology
}

\author{
Sergei V. Smirnov ${ }^{1}$, Aygul Z. Ibatova ${ }^{2}$
}

${ }^{1}$ Philosophy and Sociology Department, Kazan Federal University, Elabuga Institute, Russian Federation

${ }^{2}$ Sciences and Humanities Department, Tyumen Industrial University, Russian Federation

\begin{tabular}{l} 
Article Info \\
\hline Article history: \\
Received Feb 27, 2019 \\
Revised Aug 1, 2019 \\
Accepted Sep 21, 2019 \\
\hline Keywords: \\
Electronic technology \\
Engineering specialties \\
Laboratory works \\
Principle of systematic \\
Self-monitoring \\
Training
\end{tabular}

\begin{abstract}
The purpose of our work is to check the effectiveness of the principle of systematic in the process of teaching professional foreign language to the engineering specialties. The laboratory work contains information lexical programs for the introduction of active lexical lessons, vocabulary and grammar exercises, and questions to the texts of lessons, designated for selfcontrol and mutual control. The authors presented the results of the implementation of the system principle in the pedagogical process, namely the possibility of providing systematic construction of methodical literature and construction of intra subject links. The laboratory work, thanks to which there is an actualization and improvement of basic knowledge and skills, as well as the motivation of educational activity - is the form of realization of this principle. The students have an opportunity to demonstrate the independence in performing communicative actions in the professional sphere, provided by the program, to automate their skills, to conduct the self-study and selfmonitoring of knowledge and skills, as well as to make their correction.
\end{abstract}

Copyright $\odot 2020$ Institute of Advanced Engineering and Science. All rights reserved.

\section{Corresponding Author:}

Sergei V. Smirnov,

Philosophy and Sociology Department,

Kazan Federal University, Elabuga Institute,

Elabuga, Russian Federation.

Email: longqiu450Lia@hotmail.com

\section{INTRODUCTION}

Significant changes have occurred in the field of teaching methods of foreign languages in recent years. The priority direction is development and formation of communicative competence [1], i.e. the preference is given to communicative approach. The communicative approach in teaching foreign languages is based on the principles of interactivity, learning language in the cultural context, authenticity of communication. In the coordinates of the communicative approach some special attention is paid to the training of intercultural communicative competence, which represents the communication between representatives of different cultures, and as the knowledge of the cultural context of using a foreign language, the ability to communicate in this context. Hence there is a problem of searching for new ways of cognition and communication, which is faced by teachers in intercultural educational processes [2].

New views on the outcome of learning and the impact of intercultural relations, social cultural differences in communication between people have contributed to the emergence of new technologies of developing communicative competence, and have also led to many studies in this field, proposals of models, methods, approaches of formation of the given competence. The purpose of teaching foreign languages is the development of the student's ability to intercultural interaction and the use of the language being learned as a tool for this collaboration, which necessarily affects the content of learning and the selectin of technology for its learning by the student [3-6]. 
All works are based on intercultural comparison, intercultural didactics and intercultural knowledge of the language as an indicator of the ability of a person to participate effectively in the intercultural communication. During communication in intercultural situations, even in case if its participants possess a common language code, there are always conflicts between knowledge and ignorance, between foreign and own. Consequently, the basic vector of modern linguo-didactic and methodical scientific researches should be directed on resolution of these conflicts [7-11].

The recognition of its immersion in the social cultural context is characteristic for communicative method [12-14]. The social cultural component in the field of teaching a foreign language has a great potential in part of including students in the dialogue of cultures, their acquaintance with the achievements of national culture in the development of human culture (ibid.)

However, it is obvious that the formation of communicative competence only is not enough for the modern highly qualified person, being in demand in business sphere. The foreign language in this case acts as a means of improvement of professional competence and personal and professional development, is a necessary condition of successful professional activity of a specialist [15-17]. Based on the requirements of society and state, the higher education faces the challenge to prepare highly qualified specialists.

Mastering the foreign language by students of technical specialties is mainly directed to the resolution of pragmatic goals: development of skills to receive and transmit the information of a general character through written and verbal speech $[1,18]$. This, in turn, necessitates the special training of non-language students for professional-oriented communication in a foreign language, which supposes that the students will develop the skills of communicating in a foreign language in order to solve their professional problems [19, 20]. Consequently, the preparation of students in professional foreign language -is one of the actual challenges of the modern higher education.

Teaching of a professional foreign language - is a holistic pedagogical process. This process is characterized by the internal unity of its constituent components. The main aspects of the integrity of the pedagogical process are: content, organization, process technology [21]. Interaction and interconnection of all components and ensures the effectiveness, integrity of the pedagogical process. As any process, the process of learning has its own laws and principles, expressing the necessary links between its conditions and the result, reflect the flow of objective laws and regularities of the learning process and determine its focus on personal development [22]. It is the principles, that characterize the vectors of the teaching process, prescribe a line of action for the organization of this process in accordance with regularities of training, choosing the content, methods of training $[23,24]$. The knowledge of the principles allows the teacher to observe the phasing of the pedagogical process.

The principles of teaching are of diverse character: some principles define the whole process of teaching, the other define the teaching of a particular type of speed [25]. It is possible to allocate the following principles as the basic didactic principles of teaching a foreign language: the principle of consciousness, activity, systematic, stability, visibility, accessibility [23, 26, 27].

There are different classifications of teaching principles: a) linguistic principles, taking into account the mother tongue when learning the foreign language, communicative competence; cognitive principles: the principle of using internal motivation, the principle of automation of speech units; emotional and psychological principles: the principle of language "Me", the principle of interconnected mastering of language and culture of the country of the studied language [28].

The general didactic principles are the basis of the teaching of discipline; common methodical principles are the basis of teaching a foreign language; specific methodical are the basis of teaching a certain type of speech activity [23]. Nevertheless, in modern pedagogy and methods of teaching a foreign language have no unambiguous classification of methodical principles? The wording of the principles is constantly changing and the attempts are being made to identify and highlight the basic and common principles, based on key aspects of the methodology.

Proceeding from the pedagogical experience of work in higher educational institution of technical direction, it is possible to assert, that difficulties in training of students are connected not so much with complexity of mastering of the subject, but much with correct methodological support of the process of pedagogical education, namely the adherence to all its principles [29]. One of the basic principles is the system principle, which determines regulatory, standard and control functions and ensures the integrity of methodological and pedagogical systems $[30,31]$.

The basic and most important principle of training is the principle of systematic or the systemic principle, which provides systemic construction of programs and textbooks and establishment of inter subjective and intra subject links. The development of a systematic approach to training has allowed to structure the teaching material more clearly, to create sets of educational and visual manuals on the studied subjects. System structuring requires the ex articulation in the studied material of leading concepts and categories, establishment of their links with other withdrawals and categories (causal, functional, etc.), autopsy of their 
genesis. The system approach is considered as the direction of the methodology of special scientific perception and social practice, which is based on the research of the objects as systems.Philosophical aspects of the system approach, namely consider the object, as a system in the coordinates of structural analysis. The systemic approach was studied as a direction of methodology, social cognition and social practice, based on the study of objects as systems.

The systemic principle is reflected in the works of many scientists as a general scientific principle or methodology of cognition, reflecting the universal connection and inter conditioning of phenomena and processes. In pedagogical researches the essence of system approach is determined by the fact, that relatively independent components are considered not in isolation, but in their interconnection, development and movement. It is the systemic approach, that allows to distinguish the elements and relationships between them, that can be influenced to improve the overall behavior of the entire system; study (development) of management processes, ensuring the achievement of expected results; correlation of the obtained results with the behavior of the whole system; creating a system with improved behavior.

The systemic approach in teaching provides the teachers with the opportunity to integrate several technologies in the pedagogical process, to develop their technological pedagogical thinking. The systematic pedagogical understanding is the basis for the teachers to improve their technological pedagogical thinking and supports the transformation of their knowledge, called technological knowledge of pedagogical content. The interrelation of internal and external properties and links of pedagogical objects, their integrity is aimed at ensuring optimal functioning of those systems, which are included in the pedagogical process. The teacher is entrusted with the functions of management of the education system in order to obtain results.

Consequently, in general, the systemic approach allows to consider the phenomenon as a single whole, which is not divided into constituent parts (elements), to explain the essence of each part as an independent object without regard to other parts and to understand the essence of separate parts, without tearing away from understanding of the whole. The basic concept of this approach - is the concept of the system, moreover, there has not been an accurate understanding of the system principle to date. Thus, the purpose of our research - to reveal the essence of the principle of systematic in the process of teaching foreign language for the students of engineering specialties.

\section{METHODS}

In the course of theoretical comprehension of the problem we put forward the assumptions, requiring practical confirmation in the process of experimental work: training for the students of engineering specialties in foreign language will be more effective, if the principle of systematic will be realized through the prism of such technology of training as laboratory work. Approbation of application of the principle of systematic in the training for students of engineering specialties in foreign language with the help of such technology, as laboratory work, took place in the process of experimental and experimentation, which lasted from 2015 to 2017. Experimental work included three stages:

The first step was to determine the level of foreign language proficiency of the students, based on the established criteria and indicators. The criteria were as follows: completeness, awareness of knowledge; independence of judgments; increased interest to the study of discipline. Based on the criteria of knowledge and skills we have allocated three levels of indicators of evaluation of the results of training: high (91-100 points), medium (76-90), low (0-76).

In the process of experimental work at the formative stage the approbation of the implementation of technology -laboratory work was carried out on the basis of systemic principle; at the final stage there was a final assessment of the level of proficiency in a foreign language after the introduction of laboratory works on the basis of the system principle in the experimental and control groups, their comparison and the judgment on the effectiveness of the developed technology.

The base of experimental work was the branch of the Tyumen Industrial University in Surgut and Yelabuga branch of the Kazan Federal University. 120 students took part in experimental work. 110 children - 20 girls and 90 boys directly participated in the experimental work. This number of boys is due to a technical specialty. All students aged 18-19 years agreed to participate in the sampling, the help of psychologists was not required, as all students are adults. In accordance with the established requirements, such scope of sampling is sufficient to recognize it as representative and allows to apply the methods mathematical statistics, namely $\mathrm{x}^{2}$ Pearson criterion. This coefficient was used to find the probability that the experimental and control groups referred to the same of the same assemblage.

Such form as laboratory work has become an effective form of implementation of the principle of systematic in teaching of the foreign language. It is the technology of laboratory work that allows to update the basic knowledge and skills, to increase motivation of students ' educational activity. Moreover, such technology allows to arrange work with special literature, as well as performing various exercises, aimed at forming 
communicative competencies. In order to confirm the effectiveness of this technology students were asked to maintain a diary of their achievements and errors after completing each laboratory work. The experiment was carried out during 2015-2017 years. As a result, we counted the number of correct and incorrect answers as a percentage of the total number of correct answers.

In monitoring the results, we tracked the changes taking place in the training groups of 2016-2017, where the principle of systematic was implemented on the basis of the introduction of such a form of classes as laboratory work in the pedagogical process compared to 2015-2016, where laboratory works were not introduced yet.

The students, trained within scope of this form, having received the laboratory work, first plan the course of its implementation in accordance with the instruction (in particular, they compare and evaluate the methods of solutions known to them, consciously choose the most rational ones, consider the possible consequences of their application) and only after that to proceed to the realization of the purpose and tasks. Students can always return to the required stage of the job, check the composition of the actions performed, understand the errors and correct them. Thus, the development of fundamental competencies of students can be analyzed and adjusted in the course of work.

\section{RESULTS}

Based on the provisions of the principle of systematic, we have developed a linear structure of the course of training for the students-engineers in a professional foreign language in accordance with the formulation of the goals and objectives of the course. This structure of the course assumes, that all topics are submitted sequentially. It is understood however, that the assimilation of each subsequent section is based on the previous one. A sample of this type of programs and manuals can be classical grammars, where sections and topics do not repeat each other, have the logic of location, but not always imply repeating the sections passed in a single connection. This course consists of several laboratory works.

It should be noted, that laboratory work can act as a method, form and means of training. The purpose of laboratory works - is the application of knowledge, development of experience and skills of activity, formation of organizational, communicative skills. During performance of such works the students independently practice in practical application of the learned theoretical knowledge and skills.

In our case laboratory work is one of the forms of organization of training sessions of the abovementioned course. The form of training is understood as sustainable ways of organization of pedagogical process, types of training sessions, ways of organization of educational activity of schoolchildren and teacher, directed on pupils' mastering the knowledge and skills, on upbringing and their development in the course of education.

Laboratory work: offers the following lesson structure:

a) Communication of the topic, purpose and tasks of the laboratory work;

b) Updating of the basic knowledge and skills;

c) Motivation of students ' educational activity;

d) Familiarization of students with the instruction;

e) Selection of necessary didactic materials, means of training and equipment (in our case - linguistic dictionaries);

f) Performance of laboratory work;

g) Preparation of the report;

h) Discussion and theoretical interpretation of the obtained work results.

This form of the organization of classes is typical for technical disciplines in high school. But the conduct of such classes at the Tyumen Industrial University showed its effectiveness. Here is an example of laboratory work for the students of the direction "Operation of transport and technological machines and complexes" in the branch of Tyumen Industrial University in Surgut.

The plan of laboratory work corresponds to the above-mentioned structure of classes, the purpose and themes have been indicated. The update of knowledge is made with the help of exercises, and then comes the execution of laboratory work.

1) Theme 1. Circumstantial dependent sentences of purpose, condition, time and causes. 2. Imperative sentences with let. 3. Pronoun it. 4. Negative pronouns some, any, negative pronouns no, none. 5. Comparative conjunction

2) Update of knowledge. Exercises:

Translate the following sentences. Mind the conjunctions of the adverbial subordinate clauses.

Translate the following sentences with "let", "let's".

State the functions of "it" and translate the sentences.

Translate the sentences. Mind the pronouns "some", "any", "no". 
a) Translate the following sentences. Mind the meaning of the words in bold type.

b) Translate the international words without a dictionary.

c) State the functions of "it" and translate the sentences.

d) Translate the sentences. Mind the pronouns "some", "any", "no".

e) Translate the following sentences. Mind the meaning of the words in bold type.

3) Performance of laboratory work.

Translate the international words without a dictionary.

Text 1

Lexical and Grammar Exercises:

a) Translate the following word combinations from the text.

b) Answer the following questions.

c) Choose the proper words from those given in brackets and translate the sentences.

d) Translate the following sentences. Mind the meaning of the words in bold type.

e) Choose Russian equivalents to the following English

f) Arrange synonyms in pairs and translate them.

a. Translate the following word combinations. Mind the place of the attributes.

b. Translate the following sentences paying attention to the conjunctions of comparison.

g) Fill in the blanks with the pronouns "some", "any", "no" and translate the sentences.

a. State the functions of the pronoun "it" and translate the sentences.

b. Put the following sentences into the imperative mood with "let", "let's". Translate the sentences.

Read and translate the text. Find in the text the answer to the question: "What advantages has the aluminum? Translate the following extract using a dictionary.

After completing the laboratory work in the English language, the preparation of the report, discussion and theoretical interpretation of the obtained work results occur in a different way, than during the study of technical disciplines. In this case we suggest to carry out the monitoring and self-examination of the obtained results. In this case self-monitoring is a method of pedagogical measurement, the essence of which is to determine the level of conformity of the results of educational work to the established educational standards. The students are asked to fill in the Table 1.

Table 1. Evaluate Your Knowledge on the Scale

\begin{tabular}{lccc}
\hline Number of errors & $0-3$ & $3-6$ & $6-10$ \\
\hline Number of points earned & $100-60$ & $60-30$ & $30-0$ \\
\hline
\end{tabular}

The application of the self- monitoring during execution of laboratory work in a foreign language provides obtainment of objective information on the effectiveness of the educational process, as well as making adjustments if necessary. In order to confirm the effectiveness of the application of such form of arrangement of classes such as the laboratory work in the training of humanitarian disciplines (English), we have conducted experimental works and confirmed the reliability of the results with the help of methods of mathematical statistics. In order to carry out the pedagogical experiment, we have allocated three levels of indicators of evaluation of the results of training: high (91-100 points), intermediate (76-90), low (0-76). High level: The student shows a high degree of autonomy in performing communicative actions in the professional sphere, provided by the program, keeping business correspondence, filling in forms and forms.

The student's skills are automated; the student has a high speed of execution of the action. The student has a high degree of consciousness of skills, conscious control in case of occurring difficulties in building a statement or making a mistake, and is able to transform them into other activities; demonstrates the accuracy and quality of the actions performed. Intermediate level: The student shows an intermediate degree of autonomy in performing communicative actions in the business professional sphere, provided by the program, keeping business correspondence, filling in forms and forms, performs the actions according to the sample without assistance of the third party. The student's skills are not enough automated, the student has not a high speed of execution of the action.

The student has an intermediate degree of consciousness of skills, conscious control in case of occurring difficulties in building a statement or making a mistake, and is able to transform them into other activities with the help of the teacher; demonstrates the intermediate level of accuracy and quality of the actions performed makes insignificant mistakes. Lowlevel: The student shows a low degree of autonomy in performing communicative actions in the business professional sphere, provided by the program, keeping business correspondence, filling in forms and forms, performs the actions according to the sample with assistance of the teacher. The student's skills are not automated; the student has a low speed of execution of the action. The

\footnotetext{
Training on professional foreign language for students of engineering specialties ... (Sergei V. Smirnov)
} 
student has a low level of consciousness of skills, is not able to transform them into other types of activity; the correctness and quality of execution of actions is absent. The student needs the help from the outside.

As the data analysis shows in Table 2, the dynamics is more clearly expressed in the groups of 20162017 years of training. Accordingly, the obtained data indicate that the introduction of such a form of organization of classes in the educational process positively affects the formation and development of communicative competence in a foreign language and training in general.

Table 2. Efficiency Dynamics of Laboratory Work Implementation During the English Language Lessons in High School (\%)

\begin{tabular}{|c|c|c|c|c|c|c|c|c|c|}
\hline \multirow[b]{2}{*}{ Groups } & \multirow{2}{*}{\multicolumn{3}{|c|}{$\begin{array}{c}\text { 2015-2016 } \\
\text { (the intermediate indicator of } \\
\text { Tyumen Industrial University and } \\
\text { Kazan Federal University) }\end{array}$}} & \multicolumn{6}{|c|}{$2016-2017$} \\
\hline & & & & \multicolumn{3}{|c|}{$\begin{array}{c}\text { The Tyumen Industrial } \\
\text { University }\end{array}$} & \multicolumn{3}{|c|}{ The Kazan Federal University } \\
\hline Levels & 1 cut & 2nd cut & 3rd cut & 1 cut & 2nd cut & 3 rd cut & 1 st cut & 2nd cut & 3 rd cut \\
\hline High & 11.1 & 14.8 & 18.5 & 7.8 & 23.1 & 42.3 & 8.0 & 20.0 & 32.0 \\
\hline Intermediate & 51.8 & 51.8 & 55.6 & 46.1 & 50.0 & 50.0 & 44.0 & 44.0 & 52.0 \\
\hline Low & 37.1 & 33.4 & 25.9 & 46.1 & 26.9 & 7.7 & 48.0 & 36.0 & 16.0 \\
\hline
\end{tabular}

In order to find the probability that the experimental (2016-2017) and control groups (2015-2016) belong to the same aggregate, i.e. indistinguishable, we used the $\mathrm{X}^{2}$-Pearson Criterion (on independent sampling). For this purpose we have put forward two hypotheses: But, according to which, the distribution of the levels of evaluation indicators do not differ among themselves in the experimental and control groups and the $\mathrm{Hl}$ hypothesis, according to which the levels of evaluation are mutually different.

The formula (Annex 6) computed the estimated value of the Pearson criterion to check the statistical indistinguishability of the experimental and control groups and found $x^{2} e x p \cdot \chi^{2}$ crit. $=5,991$ at the level of statistical significance $\rho=0,05$, corresponding to $5 \%$ of the level of discrepancy of experimental data with the tabular ones. Comparison of data of the control and experimental groups by the Pearson Criterion shows that $x_{\text {exp. }}^{2}>x_{\text {crit. }}^{2}$.

It is understood however, that when comparing the experimental groups ЭГ (ТИУ) and ЭГ (КФУ) $x^{2}{ }_{\text {exp. }}<x_{\text {crit. }}^{2}$, which means the statistical indistinguishability of these sampling. However the comparison of these groups КГ (2015-2016) shows another result $-x^{2}$ exp. $>x^{2}$ crit. This shows that the experimental activities carried out by us in the pilot groups, experimental activity to implement the principle of systematic and its implementation through the introduction of laboratory works are effective in both groups, compared to other forms of classes' arrangement.

\section{DISCUSSION}

The performed analysis of methodical and pedagogical literature showed, that many questions remain in the method of teaching foreign language in high school. No textbook, even one, that represents a modern methodical concept, can satisfy all the needs of the Russian higher school, meet the requirements of the federal state standard in higher education, as in the mainstream of intercultural interaction it is wrong to limit the learning process to any grammatical rules and grammar and translation exercises that saturated so much English language textbooks. That is why, both textbooks and teaching methods should be distinguished by their flexibility, ability to interact with students and teachers, include different forms of training. It is this approach that motivated us to apply the form of organization of the process of training - laboratory work, as this form is very close to the students of engineering specialties, and is not like the traditional form of classes. The absence of such forms of work for teaching of humanitarian disciplines only shows that these studies are at an early stage of their development. Communicative forms of education are used in the method of teaching foreign language, but this form of work is ineffective for students-engineers, as in teaching methods for students of non-humanitarian disciplines the privileges are given to grammar-translation method of teaching, where students should first of all learn to translate technical texts.

The results showed that laboratory work was an effective tool for realization of this principle in the educational process. These results are consistent with other studies. The laboratory work is applied in many teaching methods, related to technical disciplines. All listed methods of carrying out of laboratory works unite - training of technical disciplines, and namely not only the performance of the work itself, but also compilation of the report and conclusions, interpretation of the received results, development of skills of critical thinking of students, based on their ability to produce reports on laboratory work increasing student motivation. 
In the practice of teaching a foreign language in high school, we took the structure of this technology from the methodology of teaching technical disciplines and transformed it into teaching a foreign language. We had to change the course of work in connection with new requirements of higher education, new requirements in the state educational standard, new estimation of knowledge - point-rating system, etc.

Students focus on performance of laboratory works, achievement of results in self-monitoring, fulfillment of tasks for independent work with the purpose of achievement of the best indicators. We believe that this development of a linear course on the basis of laboratory works has served as a positive factor for the subsequent efforts of the teacher in achieving positive results of students.

But on average, students performed laboratory works 2 hours a week; but the independent execution was allotted for another 2 hours. According to our assumptions, students neglected their own homework, so the results could be better. Consequently, we can affirm, that such a system of work is an effective tool for the development and formation of foreign skills among the students with an intermediate level of proficiency in a foreign language. The students noted the advantages of this technology, namely replenishment of vocabulary, logical construction of exercises that allow bettering memorizing professional nursery vocabulary. But I would like to note the advantages and disadvantages of the implementation of the system principle on the basis of laboratory work.

Laboratory work as a new form of organization of foreign language classes looked promising for teachers, the results should have been better. The studies of this form of lessons for technical disciplines only show that it has not been sufficiently developed for humanitarian disciplines. Therefore, further researches and transformation is needed on the teaching of a foreign language in higher school. The ability to perform and develop virtual labs should be carefully studied, as well as the possibilities of including interactive elements in this form of classes, etc. Further studies, dedicated to these aspects would allow teachers to organize and arrange all acts of training and components of their operations.

\section{RESEARCH LIMITATIONS}

In the course of work there were some discrepancies, for example, some students did not fully perform laboratory work in classes and did not perform their homes at all, and the results showed averages in the classroom, i.e. systemic performance of laboratory work was not the main determinant factor of development of skills and skills of communication in a professional foreign language. First of all we explain it thanks to their initial good level of foreign language proficiency. The students constantly improve their skills by watching feature films in a foreign language, keep correspondence with foreign students, etc.

The challenge for students was to exercise self-monitoring and to monitor and regularly perform independent work. We suppose, that these negative aspects were related to the disorganization of students in the first course, their difficult adaptation after graduation from school, the inability to readjust from the school system of education to the one of university.

Despite the significant results obtained here, this study has limitations that may be useful for future researches. An interview with each student of the experimental group could provide a deeper understanding of the present and the prospects of working with the technology of laboratory work, based on the systemic principle. For example, the personal aspect of applying this technology in training, the disadvantages of this technology or the prospects for development and improvement.

From the experience of working on this technology, it is possible to easily identify the more independent or self-motivated students, thus providing a potential understanding of the components of the moral and psychological state of students, having a higher level of proficiency in foreign language; the relation of the results of students' training in terms of new vocabulary.

In addition, we believe, that it would be appropriate to use and apply a differentiated approach to this technology in accordance with the level of their abilities and capabilities in order to maximize the development of each individual at all stages of education. This approach is necessary for higher-level students, so emphasizing this aspect in future researches can have a positive impact on future results, as well as contribute to a more effective formation of skills and proficiency in a foreign language.

\section{CONCLUSIONS}

So, the main provisions of the systemic approach allowed us to consider the teaching of a professional foreign language as a system, as well as to realize the principle of systematic in the process of teaching a foreign language for students-engineers through such a form of classes organization, as the laboratory work. The comparative analysis of the data on the control group (2015-2016) and the experimental group (2016-2017) shows that in the groups, where the implementation of the principle of systematic was carried out through the prism of such a form of organization of classes as the laboratory work, the best education results were obtained. 
It should be noted, that in the control group, where the process of professional training was traditionally carried out without any innovations, the positive results in the educational process also took place. This is due to the fact that the training for a professional foreign language in the process of professional training is carried out, although it is not systematic.

The confirmation of the objectivity of the obtained results was received by means of their statistical processing using the Pearson criterion, which proved the statistical significance of the differences in the data, characterizing the levels of the assessment of training in experimental groups, compared to the control teams. This served as a basis for the statement of the effectiveness of the principle of systematic in the pedagogical process and its implementation in the classroom - the laboratory works.

\section{LIST OF ABBREVIATION}

ЭГ (ТИУ) - Expert group of the Development Program of the Tyumen Industrial University

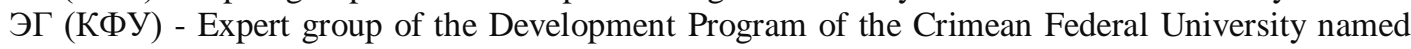
after V.I. Vernadsky

\section{REFERENCES}

[1] Lazarevicć N. Development of intercultural communicative competence: A course for pre-service EFL (English as a foreign language) teachers. InIntercultural Competence in Higher Education 2017 Jul 20 (pp. 214-218). Routledge.

[2] Torres F, Tovar LA, del Rio MS. A learning evaluation for an immersive virtual laboratory for technical training applied into a welding workshop. EURASIA J. Math. Sci. Technol. Educ. 2017 Feb 1; 13(2):521-32.

[3] Aguilar MJ. Dealing with intercultural communicative competence in the foreign language classroom. InIntercultural language use and language learning 2008 (pp. 59-78). Springer, Dordrecht.

[4] Houghton, S. The role of intercultural communicative competence in the development of world englishes and lingua francas. 3L: Language, Linguistics, Literature, 2009, 15(1), 69-95.

[5] Araja, A., \& Aizsila,A. Intercultural communicative competence. Research for Rural Development 2010, 2, 220-224

[6] Young TJ, Sachdev I. Intercultural communicative competence: Exploring English language teachers' beliefs and practices. Language awareness. 2011 May 1; 20(2):81-98.

[7] Blake Armstrong G, Kaplowitz SA. Sociolinguistic inference and intercultural coorientation. A Bayesian model of communicative competence in intercultural interaction. Human Communication Research. 2001 Jul;27(3):350-81.

[8] Bhattacharyya E, Idrus HB. To speak like an engineer: Communicative competence in technical oral presentations through the lens of students and industry practitioners. In Proceedings of 2013 IEEE International Conference on Teaching, Assessment and Learning for Engineering (TALE) 2013 Aug 26 (pp. 796-799). IEEE.

[9] Mitchell, P. J.,Pardinhoa,L. A.,Yermakova-Aguiara,N. N., \&Meshkova,L.V. "Language learning and intercultural communicative competence: an action research case study of learners of Portuguese". Procedia-social and behavioral sciences, 2015,200, 307-312.

[10] Lindner R. English learner, English speaker, intercultural speaker, digital native: Student construction of communicative competence gained through reflection on computermediated exchange. Intercultural studies and foreign language learning. 2015; 16.

[11] Edi e. investigating intercultural comunicative competence model for english student at stkip yapis dumpu ntb (doctoral dissertation, universitas negeri makassar), 2017.

[12] Farquhar MA. Rereading "On communicative competence": the sociocultural dimension. Asian Studies Review. 1992 Apr 1; 15(3):16-23.

[13] Van Compernolle RA, Williams L. Teaching, learning, and developing L2 French sociolinguistic competence: A sociocultural perspective. Applied linguistics. 2012 Jan 24; 33(2):184-205.

[14] Galanina E, Dulzon A, Schwab A. Forming engineers' sociocultural competence: Engineering ethics at tomsk polytechnic university. In IOP Conference Series: Materials Science and Engineering 2015 (Vol. 93, No. 1, p. 012078). IOP Publishing.

[15] TexidorPellón, R., \& Reyes Miranda, D. Postgraduate Education of English for Specific Purposes for professionals of the School of Dentistry. Revista Cubana de Educación Médica Superior, 2015, 29(3), 650-659.

[16] Laborda JG, Litzler MF. Current Perspectives in Teaching English for Specific Purposes. Onomázein: Revista de lingüística, filología y traducción de la Pontificia Universidad Católica de Chile. 2015(31):38-51.

[17] Zelenkova A. Particularities of English for Specific Purposes and Development of Intercultural Competence. European Scientific Language Journal. 2015:36.

[18] Alqahtani MA. Teaching English for Specific Purposes: Attitudes among Saudi Engineering Students. English Language Teaching. 2015;8(7):76-94.

[19] Belcher DD. English for specific purposes: Teaching to perceived needs and imagined futures in worlds of work, study, and everyday life. TESOL quarterly. 2006 Mar; 40(1):133-56.

[20] Bielousova R. Gearing English for specific purposes teaching to the requirements of engineering practice. InEducation and Acreditation. 12th International Multidisciplinary Scientific Geo-Conference SGEM 20122012 Jun (pp. 1101-1104). 
[21] Shih RC. The Effect of English for Specific Purposes (ESP) Learning-Language Lab versus Mobile-Assisted Learning. International Journal of Distance Education Technologies (IJDET). 2017 Jul 1; 15(3):15-30.

[22] Roche S. The contribution of lifelong learning to development-personal and communal, 2018, 64(1).

[23] Passov, E. The program - a concept of communicative foreign language education, 2000, (pp. 170). M.: Prosveshenie.

[24] Galskova ND, Gez NI. Teoriya obucheniya inostrannym yazykam: lingvodidaktika i metodika (Theory of teaching foreign languages: linguodidactics and methodology). M.: Izdat. Tsentr «Akademiya. 2005.

[25] Gurvich, P.B. On four general methodical principles of teaching of foreign language. Foreign languages at school, 2003, 6, $32-37$.

[26] Starkov, A.P. Teacher's book (pp. 208).Part 3. Publishing house ACT, 2004.

[27] Long, M.H. Methodological Principles for Language Teaching, 2009, (pp. 371-394). The Handbook of Language Teaching.

[28] Larsen - Freeman, D. Techniques and Principles in Language Teaching. 2000, (pp. 252). 2ndedn Oxford: Oxford University Press.

[29] Yingprayoon J, Latipov ZA, Sabirova FM. Research on the contribution of the Nobel prize laureates in physics to the development of modern equipment and technologies in technical universities. European Journal of Science and Theology. 2014 Dec 1; 10(6):193-202.

[30] Heaton DP. Stop Teaching: Principles and Practices for Responsible Management Education, 2017.

[31] Ellner, M. Understanding the school curriculum: Theory, politics and principles. Journal of educational research, 2018, 111(1). 